University of Nebraska - Lincoln

DigitalCommons@University of Nebraska - Lincoln

\title{
$5-2010$
}

\section{Exploring social constructions of followership: A qualitative study}

\author{
Melissa K. Carsten \\ Winthrop University, carstenm@winthrop.edu \\ Mary Uhl-Bien \\ University of Nebraska-Lincoln, mbien2@unl.edu \\ Bradley J. West \\ University of Nebraska-Lincoln \\ Jaime L. Patera \\ University of Nebraska-Lincoln \\ Rob McGregor \\ Spirit West Management, Canada
}

Follow this and additional works at: https://digitalcommons.unl.edu/leadershipfacpub

Part of the Management Sciences and Quantitative Methods Commons

\footnotetext{
Carsten, Melissa K.; Uhl-Bien, Mary; West, Bradley J.; Patera, Jaime L.; and McGregor, Rob, "Exploring social constructions of followership: A qualitative study" (2010). Leadership Institute Faculty Publications. 20.

https://digitalcommons.unl.edu/leadershipfacpub/20
}

This Article is brought to you for free and open access by the Leadership Institute at DigitalCommons@University of Nebraska - Lincoln. It has been accepted for inclusion in Leadership Institute Faculty Publications by an authorized administrator of DigitalCommons@University of Nebraska - Lincoln. 


\title{
Exploring social constructions of followership: A qualitative study
}

\author{
Melissa K. Carsten, ${ }^{1}$ Mary Uhl-Bien, ${ }^{2}$ Bradley J. West, ${ }^{2}$ \\ Jaime L. Patera, ${ }^{2}$ and Rob McGregor ${ }^{3}$ \\ ${ }^{1}$ College of Business Administration, 518 Thurmond Building, Winthrop University, Rock Hill, SC 29733, USA \\ ${ }^{2}$ Department of Management, University of Nebraska-Lincoln, Lincoln, NE, USA \\ ${ }^{3}$ Spirit West Management, Canada \\ Corresponding author - M. K. Carsten, tel 803 323-4817, fax 803 323-3960, e-mail carstenm@winthrop.edu
}

\begin{abstract}
This study adopts a qualitative approach to deconstruct the meaning of followership. Interviews were conducted with employees in various industries to examine how individuals socially construct their roles as followers and to explore followership schemas and contextual influences that relate to these constructions. Results suggest that while some individuals socially construct definitions around passivity, deference and obedience, others emphasize the importance of constructively questioning and challenging their leaders. With regard to personal qualities that are thought to make followers effective, major themes such as obedience, expressing opinions, and taking initiative were found to be most disparate across different groups of followers. Results also revealed that contextual factors may affect both followership constructions and behavior in the follower role. These findings have important implications regarding a need to examine the construct of followership in leadership research, as well as raise interesting possibilities for advancing an "expanded" view of leadership in organizations.
\end{abstract}

Keywords: Followership, Leadership, Social construction, Social cognition, Qualitative research

While the role of followers in the leadership equation has long been recognized (Hollander, 1992; Parker Follett, 1949) and recent work has extended follower-centered approaches to leadership (Howell and Shamir, 2005; Meindl, 1995; Shamir et al., 2007), an area that has not yet been explored in leadership research is that of followership (Baker, 2007). Followership research, consistent with Graen and Uhl-Bien's (1995) description of "follower-based" approaches (p. 223), adopts the follower as the primary focus and explores how followership behaviors are related to organizational outcomes of interest (e.g., leadership, performance). A followership approach differs from "follower-centric approaches to leadership" (Meindl, 1995) in that the issue of interest is not follower perspectives of leadership but instead follower perspectives of followership. Rather than considering how followers view their leaders and their leaders' behaviors, a focus on followership would consider how followers view their own behaviors and roles when engaging with leaders (UhlBien \& Pillai, 2007).

A focus on followership helps increase our understanding of the leadership process by adding to current typologies of leader styles and behaviors (Pearce \& Conger, 2003), a description of follower styles and followership behaviors. Such a perspective helps "reverse the lens" (Shamir, 2007) in leadership research by addressing the role that followers play in creating and maintaining effective followership and leadership outcomes. Moreover, it addresses calls by Collinson (2006) and others (Lord \& Brown, 2004) for a need to generate a deeper understanding of follower identities and the complex ways these identities affect leaders and the leadership process.

Given that empirical research on followership has not yet been advanced, the present study reports the findings of an exploratory investigation into the nature of followership. Specifically, we investigate socially constructed definitions of followership, and examine the followership schema and contextual variables that are related to these constructions. Following suggestions of Bresnen (1995) and others (e.g., Bryman, 1986) that "leadership can encapsulate a diverse range of meanings and multiple frames of reference" (Bresnen, 1995, p. 496), we explore whether socially constructed definitions of followership might also assume different meanings depending on an individual's underlying assumptions of what it is to be a follower (e.g., see Bresnen, 1995; Bryman, 1986; Collinson, 2006; Meindl et al., 1985; Smircich and Morgan, 1982). 
Thus, similar to Bresnen's (1995) method of investigating managers' socially constructed definitions of leadership, we adopt a qualitative methodology in an effort to achieve a more grounded understanding of what followership means to those acting in such roles.

We begin by positioning the study of followership in the context of follower-centered approaches to leadership and leadership theories that privilege the role of followers (e.g., shared leadership and self-management). We show that while follower-centered research examines the effects of follower characteristics on their interpretations of leaders, and shared leadership and self-management expand leadership beyond the role of hierarchical leaders, these approaches remain leader-centric in that they do not examine the cognitions or behaviors associated with "followership" (i.e., the behaviors of individuals acting in relation to leaders). To address these cognitions and behaviors we follow the suggestion of UhlBien and Pillai (2007) and consider the social constructions individuals make of followership. We do this by theoretically exploring how followership schema and contextual factors may be associated with followership constructions in organizational settings. We then use interview data gathered from individuals acting in follower roles in various industries and across organizational levels to analyze reports of followership schema, the types of constructions individuals hold of followership, and the personal qualities/behaviors and contextual variables related to these constructions. We conclude by discussing the implications of our findings for future research and practice aimed at further developing and investigating the construct of followership.

\section{Focus on followership}

Research on follower-centered perspectives of leadership has explored how followers construct leadership (Meindl, 1995), how personal characteristics of followers influence perceptions of leadership (Schyns \& Felfe, 2006), and how followers can engage in self-leadership and shared leadership (Manz and Sims, 1980; Pearce and Conger, 2003). While this work has advanced leadership research by exploring follower perceptions of leaders and leadership, it offers little in the way of understanding followership. In particular, we still know very little about how followers enact their own roles as part of the leadership equation.

To address behaviors and issues related to followership we need to have a better understanding of what followership is and how it differs from existing research on follower-centered perspectives. Therefore, in the sections below we review work on the follower-centered approach to leadership and show how followership perspectives differ in their assumptions and focus. We also explain why adopting this different perspective is important with respect to enhancing knowledge and advancing understanding of a construct of followership.

\subsection{Follower-centered perspectives}

In the 1990s a stream of research in leadership began to emerge that constitutes a follower-centered approach to leadership (Shamir et al., 2007). This work, initiated by Jim Meindl (1995) and extended by others (Howell and Shamir, 2005; Lord and Brown, 2004; Pillai et al., 2007), offers a framework for generating propositions regarding the inputs, mechanisms and outcomes of follower constructions of leadership. Meindl's propositions have been explored by a number of researchers interested in understanding how follower traits, emotions, and attitudes influence their perceptions of, or preferences for, certain types of leaders (Ehrhart and Klein, 2001; Kark et al., 2003; also see Bligh \& Schyns, 2007 for a review).

For example, several researchers have discovered that follower traits such as extraversion (Schyns \& Felfe, 2006) as well as self-efficacy and motivation (Dvir \& Shamir, 2003) enhance perceptions of transformational leadership. Similar research by Phillips and Bedeian (1994) shows that follower extraversion is positively related to the quality of relationship they develop with their leader. With regard to charisma, Pastor, Mayo, and Shamir (2007) concluded that emotional arousal in followers increased perceptions of charismatic leadership. These studies suggest that certain follower traits or emotions can bolster perceptions of effective leadership (i.e., the halo effect). Recent findings by Bligh, Kohles, Pearce, Justin, and Stovall (2007) also suggest that follower attitudes can have a negative effect on perceptions of leadership (i.e., the horns effect). In particular, Bligh et al. (2007) found that follower job dissatisfaction and low self-efficacy were related to heightened perceptions of aversive leadership.

Despite the fact that this work and the follower-centric approach in general draws much needed attention to the role of followers in the leadership process, it is still primarily leader-centric in its focus (Uhl-Bien \& Pillai, 2007). This is clearly reflected in Meindl's (1995) descriptions of the follower-centric model. The follower-centric approach focuses on constructions followers make with respect to (a) leadership as a way to understand and address organizational issues and (b) the criteria or "theory-in-use" through which leaders are evaluated. In the follower-centric model, "variations in the constructions of leadership are the immediate, dependent variables of interest" (p. 333, emphasis added). In other words, the focus in follower-centric work is still constructions of leadership; as a result, research has yet to advance an understanding of follower-centered perspectives of followership.

Other research streams that are follower-centric in nature and draw attention to the behaviors of individuals acting in non-hierarchical ("non-leadership") positions are theories of shared leadership (Pearce \& Conger, 2003) and self-leadership/self-management (Lovelace et al., 2007; Manz, 1986; Manz and Sims, 1980). Both of these theories privilege the role of the "follower" (i.e., subordinate) by recognizing that leadership behaviors can occur outside of formal managerial roles. As described by Pearce and Manz (2005), traditional leadership models have been narrowly focused on individuals in formal leadership positions but, given the new realities of organizational contexts, "followers should also be included in leadership development efforts in order to prepare them to exercise responsible self-leadership and to effectively use shared leadership" (p. 130). 
The concept of self-leadership has emerged out of the self-management and "superleadership" work of the 1980s (Manz, 1986; Manz and Sims, 1980). Grounded in concepts of self-control (Lovelace et al., 2007), self-management involves regulating one's behavior to reduce discrepancies from externally set standards (Manz, 1986) by encouraging behaviors such as self-observation, self-goal setting, incentive modification, and self-rehearsal (Manz and Sims, 1980; Neck et al., 1999). At the heart of this approach is the idea that leaders should develop skills in followers that promote their capacity to take more responsibility for their own direction and motivation (Lovelace et al., 2007). "Self-leadership implies that leadership can be self-imposed and thus does not require the traditional roles of leader and follower. That is, so called followers, at least to some degree, can be their own leaders" (Lovelace et al., 2007, p. 379).

Shared leadership has emerged more recently and refers to a dynamic and interactive influence process among members who lead one another to help reach the goals of the group or organization (Pearce \& Conger, 2003). Its focus is primarily on distributed leadership processes that occur among members of teams (Avolio et al., 1996; Ensley and Pearce, 2001; Hooker et al., 2003; Pearce, 1997; Pearce and Sims, 2002; Pearce et al., 2004; Shamir and Lapidot, 2003). Findings on shared leadership show that in the right types of environments (e.g., shared purpose, social support and voice), team members can demonstrate shared leadership behaviors with one another that result in enhanced team productivity and a reduced need for external leaders (Carson, Tesluk, \& Marrone, 2007).

\subsection{Followership perspectives}

While the above approaches do bring followers (i.e., subordinates) into the equation and can be informative to the study of followership, they are still leadership models in that the behaviors they focus on are leadership behaviors (e.g., shared leadership or self-leadership) and not followership behaviors. Followership behaviors differ in that they do not address independent activities of those occupying "subordinate" positions but behaviors of individuals acting in relation to a leader(s). In other words, followership behaviors are not about how individuals interact relative to their work (e.g., self-management and self-leadership) or other coworkers (e.g., shared leadership) but relative to those with higher status - with respect to leaders. For example, followership behaviors can include the way followers choose to take responsibility relative to leaders (e.g., "it's not my job"), the way they communicate with leaders (e.g., expressing or repressing opinions), their approaches to problem-solving with respect to leaders (e.g., proactive problem-solving versus upward delegation), etc.

As described by Uhl-Bien and Pillai (2007), because the roles of leader and follower necessarily involve a status differential (with leaders having higher status), prototypical followership behaviors must involve some form of deference to the leader - as they say, once at least some semblance of deference is gone, so is followership (see also Rost, 1995). The degree to which followers show deference can vary, however. Some followers may construct and enact followership in a more traditional "subordinate" sense, demonstrated by behaviors such as reduced responsibility-taking, conformity, and reluctance to speak up, while others may construct a more "dynamic" and "courageous" role of followership in which they see themselves more as partners in the relationship or even co-leaders (Chaleff, 1995; Dixon and Westbrook, 2003; Uhl-Bien and Pillai, 2007).

Despite these suggestions and possibilities, we continue to lack empirical evidence regarding how individuals actually view followership roles in organizational settings. We know little about socially constructed definitions of followership, or the cognitive schema and contextual variables that are related to these constructions. Therefore, in the present study we examine the social constructions individuals make when acting in a follower role.

\section{Social constructions of followership}

The social construction perspective posits that individuals create and interpret reality as they interact with their environments (Berger \& Luckmann, 1966). Based on the premise that social order is a human product, Berger and Luckmann (1966) suggest that individuals are socialized to construct reality around institutionalized norms for thinking, feeling, and behaving. According to Weick (1993), social constructions in organizations are best explained by the interaction between social schema that drive perceptions and information processing and contextual attributes that make certain information salient to the constructor. Schema and context do not operate in isolation (Lant \& Shapira, 2000); instead, generalized schemas form the foundation for individuals to socially construct roles and relationships within a given context (Lord \& Hall, 2003). With regard to followership, schema help us understand followership behavior in general. However, context will influence constructions around specific followership behaviors that are appropriate or acceptable in a specific environment. In this sense, both schema and context influence how one socially constructs a definition of followership and, by extension, how they enact the follower role. Thus when speaking about their socially constructed definitions of leadership and followership, individuals reveal both their underlying schema and the aspects of the context that make schematic traits and behaviors more or less appropriate (i.e., likelihood that behaviors are enacted, or reinforced in a given context) (Weick, 1995).

With regard to social constructions of leadership, Bresnen (1995) examined the leadership schema of construction managers and found that some leaders construct their role around decision making and the importance of being a change agent, while others view having authority and control over followers as essential to practicing leadership. Bresnen concluded that leadership holds a 'multiplicity of meaning' by individuals who occupy the position, and that variations in leaders' behavior may be a product of divergent schema and context-specific constructions. What is notable about Bresnen's (1995) method is his examination of social constructions among individuals acting in leadership roles and the ability to understand patterns of relationships between schema, context, and behavior. 
In the current study, we seek to take a similar approach by directly investigating followers' social constructions of followership, and investigating the followership schema and contextual variables that are related to these constructions. Given Bresnen's finding that leadership holds various meanings across different managers, we also expect to find differences in the way that individuals socially construct followership. These differences may depend on both individual level followership schemas and relevant contextual variables that operate in the followers' organizations.

\subsection{Followership schemas}

Followership schemas are generalized knowledge structures that develop over time through socialization and interaction with stimuli relative to leadership and followership (cf. Fiske \& Taylor, 1991). Louis (1980) suggests that organizations may influence these schemas by setting norms and standards of behavior for individuals in different hierarchical roles and then reinforcing those standards. For example, there is evidence to suggest that we are socialized to view hierarchical systems such as organizations in terms of the status inequalities (Bacharach et al., 1995; Ravlin and Thomas, 2005) and power differentials (Biggart \& Hamilton, 1984) that exist between individuals in various hierarchical positions. Indeed, research on the social construction of leadership has demonstrated that individuals maintain a romanticized notion of leadership where the word leader tends to activate a schema of heroism, notoriety, and success (e.g., Meindl and Ehrlich, 1987; Meindl et al., 1985). As a corollary to the romance of leadership, Uhl-Bien and Pillai (2007) suggest that social schema may also contribute to the subordination of followership: the view that followers are largely ineffectual.

The image that followers are less responsible, accountable, and effectual than leaders is reinforced by a top-down approach to leadership that is grounded in hierarchical notions that status, power, influence, and prestige are reserved for those at the upper echelon (Courpasson and Dany, 2003; Pearce and Manz, 2005; Wortman, 1982). Because hierarchical systems reinforce the view that leaders have greater knowledge and expertise than followers, it is possible that subordinates create and maintain a schema of followership that is defined by obedience, deference, silence, and powerlessness (Courpasson and Dany, 2003; Hirschhorn, 1990; Tyler, 1997; Uhl-Bien and Pillai, 2007). For example, several lab studies have found evidence that simply assigning someone the role of "follower" invokes a cognitive schema that aligns with the notion that leaders have more knowledge and accountability than followers (Konst \& Van Breukelen, 2005) and that followers should be deferent and obedient (Gerber, 1988; Morand, 1996). Furthermore, research on upward communication in organizations suggests that followers often refrain from transmitting negative information upward because of their vulnerability and lack of power (see Glauser, 1984 for a review; Cohen, 1958; Kelley, 1951). This research suggests that subordinates modify or omit information they send upward because they fear being alienated by their leaders (Tynan, 2005), losing resources (Morrison \& Milliken, 2000), damaging relationships (Milliken et al., 2003; Tynan, 2005), or diminishing their mobility potential (Glauser, 1984).

Whereas these findings support the possibility that individuals maintain a schema of followership that is passive (obedient) in nature, there is also reason to believe that followers could hold more proactive schemas in which they believe their role is to engage more interactively with leaders (Chaleff, 1995). Followers who hold such views may believe that leadership is achieved through mutual influence (Greene, 1975; Lowin and Craig, 1968) rather than authority and control, and see their role with leaders as partners (Uhl-Bien, Graen, \& Scandura, 2000), co-producers of leadership (Shamir, 2007), or co-leaders (Heenan \& Bennis, 1999). Research findings supporting this idea include studies showing that at least some followers use upward influence to obtain needed resources (Allen and Porter, 1983; Kipnis et al., 1981), speak up with ideas or solutions to problems (Van Dyne \& LePine, 1998), and challenge the status quo for the good of the organization (Morrison \& Phelps, 1999).

Overall, there is strong reason to believe that followers will report different schema of followership, ranging from more hierarchical views of followership as subordination and obedience (Konst \& Van Breukelen, 2005) to more contemporary views that followers are partners and co-producers of leadership outcomes (Graen and Uhl-Bien, 1995; Shamir, 2007). However, while schema and prototypes provide the foundation for creating social constructions of followership, it is also important to consider whether organizational variables (e.g., climate and leadership style) influence context-specific constructions and behavior (Holyoak \& Gordon, 1984).

\subsection{Organizational context}

According to Weick (1995), the context in which an individual operates will influence not only how one socially constructs definitions of different roles (i.e., leader or follower), but also how individuals enact such roles. Thus, the context created by the leader and the organization may influence social constructions by activating followership schema that are relevant to particular situations and influence how individuals behave in their followership roles (cf. Bresnen, 1995).

Although there are a number of different variables that work together to create organizational context (Porter \& McLaughlin, 2006), it may be that certain elements of the context will have more influence with respect to how one socially constructs followership. In particular, organizational climate and leadership styles are two variables that may play an important role in how individuals form followership constructions that are more passive or proactive in nature.

For example, organizations that maintain a tight bureaucracy or reinforce authoritarian leadership styles create a climate of top-down decision making that can stifle innovation and personal initiative taking (Blau, 1968). Such contexts reinforce the notion that leaders are more capable and competent than followers, and provide little opportunity for followers to make a substantial contribution to organizational processes. Individuals who maintain a passive schema of followership might experience a high degree of fit in this type of context given their existing belief that followers should 
be obedient and deferent in nature, and ascribe to the power and status differences typically created by bureaucratic organizations (Blass, 2000; Milgram, 1965; Ridgeway and Walker, 1995). However, followers with proactive schema might find that bureaucratic contexts can stifle initiative taking. In such cases they may find themselves having to socially construct their roles around the degree of proactivity that is acceptable or achievable in their organization. For example, followers who maintain proactive schema might become frustrated with organizations that reinforce status hierarchies and leaders who provide few opportunities for followers to contribute to the leadership process (Berger, Ridgeway, \& Zelditch, 2002). Thus, proactive followers may need to shift their definition of followership to a modified version that involves being proactive without overstepping the role boundaries that are created by the organization.

In contrast to climates of authority and bureaucracy, an empowering climate may blur the lines between leaders and followers and encourage constructions of followership that are more participative in nature (Collinson, 2006; Yun et al., 2006). Pearce and Manz (2005) contend that organizations with climates of empowerment and autonomy, as well as leaders who allow for collaboration, will provide opportunities for followers to be proactive, get involved in decision making, and, in some cases, engage in leadership-type behaviors (see also Spreitzer \& Doneson, 2005). Such contexts may be defined by a climate of initiative taking (Baer and Freese, 2003; Morrison and Phelps, 1999), ownership (Mayhew, Ashkanasy, \& Bramble, 2007), and information sharing and collective accountability (Blanchard, Carlos, \& Randolph, 1999). Research on empowerment climates, for example, suggests that organizations can positively influence job satisfaction and performance by sharing power, knowledge, and information among all organizational members (Seibert, Silver, \& Randolph, 2004).

Empowering contexts would support proactive followership schema and influence constructed definitions of followership that involve proactive problem-solving, decision making, and personal initiative (Roberts and O'Reilly, 1974; UhlBien and Pillai, 2007). However, individuals with passive followership schema may resist opportunities to participate in the leadership process and may subsequently construct followership around the passive behaviors that are important to them even when their leaders or organizations call for more proactivity.

Leaders will likely play a large role in how followers perceive, and behave in these contexts. Just as an empowering work climate may provoke more participative constructions of followership (Seibert et al., 2004), it is possible that an empowering leader might encourage followers to engage in more proactive behaviors. Empowering leaders are said to share power with followers, thereby granting autonomy and increasing intrinsic motivation (Spreitzer and Doneson, 2005; Thomas and Velthouse, 1990). As opposed to more authoritarian leaders (Vroom \& Mann, 1960), empowering leaders are not preoccupied with demonstrating their authority or ruling with an iron fist; rather they provide autonomy and encouragement to followers, and share information to build efficacy and strengthen performance (Srivastava, Bartol, \& Locke, 2006).

In sum, questions regarding the role that followership schema, organizational climate and leader style play in the social construction of followership are provocative. However, given that social constructions of followership have not been studied in the extant literature, the relationship between schema and context in relation to social constructions and behavior remains largely unknown. Thus, we must begin to investigate these issues by exploring social constructions of followership and uncovering the underlying schema and contextual influences that are related to these constructions.

\section{Present study}

The present study uses qualitative methodology to deconstruct how followers define their roles in organizations. According to Bresnen (1995), the goal of deconstruction is to extract the "multiplicity of meaning" from any construct or term. To accomplish this, we employed a qualitative interviewing technique to uncover participant's social constructions of followership. This technique is said to be appropriate for exploratory theory building research as it allows major themes to emerge from the data (Bryman, 1986; Bryman, 2004; Conger, 1998; Hunter et al., 2007).

Followers in this study were operationalized as individuals acting in a subordinate role (Bjugstad et al., 2006; Bresnen, 1995; Hollander and Webb, 1955). While we understand there may be criticisms regarding this operationalization (e.g., subordinates are not always followers, just as managers are not always leaders; Bedeian \& Hunt, 2006), we chose to investigate how employees acting in subordinate roles socially construct a definition of followership as a first step toward creating a more holistic understanding of followership in organizations. Thus for the purposes of this study, we will investigate how subordinates (i.e., followers) socially construct a definition of followership under organizational managers (i.e., leaders).

\section{Methods}

\subsection{Participants}

Semi-structured interviews were conducted with 31 participants in the U.S. and Canada working in a variety of industries and occupying a range of organizational levels. Given the early stage of empirical work on followership we wanted to enhance the generalizability of our findings by gathering input from a wide range of respondents. Therefore, we used a cross-sectional qualitative sampling method, which involves sampling from diverse backgrounds, occupations, and organizational levels in an effort to obtain a broad domain of opinions and perspectives (Bryman, 2004). Participants represent a variety of public and private sector organizations and industries including education, high-technology, financial services, mass media, consulting, and health care. The average tenure among participants with their current organizations was approximately 9 years (s.d. $=6.1$ ) and average tenure working with their current supervisor was 3.5 years $($ s.d. $=2.69)$. 
We assessed the degree and nature of interaction between participants and their respective leaders in several ways. First, to determine the amount of interaction respondents had with leaders we asked them to indicate the number of hours per week they spend interacting with their immediate manager. Interview responses showed that $60 \%$ of participants reported spending 1-10 h per week interacting with their leader, $17 \%$ spending between 11 and $20 \mathrm{~h}$ per week, and $23 \%$ spent $21-$ $30 \mathrm{~h}$ interacting per week. To assess whether respondents worked in the same immediate location as the leader(s) they identified during the interviews, we asked about co-location; we found that $78 \%$ reported they work in the same location as their leaders. Finally, to obtain a general sense of amount of delegation, we asked them to indicate on a six-point scale ranging from 1 (not at all) to 6 (a very large extent) the extent to which the leaders they identified engaged in delegating tasks and activities to them as followers. This resulted in an average level of delegation of 3.98 (with a range of 1-6 and s.d. =1.19).

Data were gathered from individuals across non-supervisory, supervisory, and middle management positions to increase the range of responses and information available for our qualitative analysis (non-supervisory $=15$, supervisory $=8$, middle management $=8$ ). We also attempted to control for gender by ensuring our sample had an adequate number of men and women (the sample was nearly evenly split among males, $n=17$, and females, $n=14$ ). Because some respondents were managers, steps were taken to ensure that participants responded to interview questions by thinking about their role as a subordinate. Specifically, we began each interview by asking respondents to identify the individuals to whom they report, and to think about their role with respect to their interactions with leaders in their organizations (e.g., their immediate supervisor, managers, directors, etc.).

\subsection{Procedure}

Respondents were contacted either by email or phone and invited to participate in an interview regarding their role in their organizations. Interviews ranged from $25 \mathrm{~min}$ to an hour in length and were based on a semi-structured protocol with 9 core questions (see Appendix A). These questions were designed to elicit participants' social constructions of followership, perceptions of the benefits and/or drawbacks of being in a follower role, and the personal qualities and behaviors they believe make followers effective. In addition, respondents were asked general questions regarding organizational variables that facilitated or impeded success in the follower role. The majority of contextual coding themes regarding climate and leadership style were extracted from answers to these questions. All interviews were tape recorded and transcribed for coding.

Prior to beginning interviews, the interview team met to talk through interviewing strategies and the importance of not leading respondents to answer questions in a specific way. Following the recommendations of Lee (1999), interviewers participated in 4 hours of training where they were instructed to (1) introduce the study to participants and explain its purpose, ensure confidentiality, and record the interview with note-taking and tape recorders; (2) avoid leading questions as a means of probing respondents, and (3) effectively steer the interview to keep respondents on track without biasing their responses. The interviewers were also briefed on the potential pitfalls in the interview process (e.g., going off topic), and how to avoid biasing the responses (e.g., through verbal and non-verbal cues). Interviewers were instructed to interview only one individual at a time, and to conduct the interview in a quiet place where the interviewer and interviewee could have privacy.

Interviews were conducted until theoretical saturation was met (Strauss \& Corbin, 1998). According to Strauss and Corbin (1998), theoretical saturation is reached when the addition of subsequent interviews fails to add new and distinct variance to the coding categories created by previous interviews. In the present study, saturation was reached at 25 interviews. However, to ensure that we obtained the desired range of responses, 6 additional people were interviewed to provide balanced representation across organizational levels (non-supervisory, supervisory, middle management).

\subsection{Coding and analysis strategy}

Qualitative coding of interview data was conducted using a method commonly referred to as "inductive analysis" (Lee, 1999; Patton, 2002). Inductive analysis is consistent with a grounded theory approach in that major themes are discovered "through an analyst's interactions with the data" (Patton, 2002, p. 453). According to Katz (1983), inductive analysis allows the researcher to continually create and refine categories in an effort to develop a theory that explains a certain phenomenon. Whereas this method does not allow for a comprehensive explanation of a phenomenon, consistent with our intent in this study, it provides a starting point from which researchers may begin to develop hypotheses regarding the constructs discovered and how these constructs are related to others.

Following the steps outlined by Goetz and LeCompte (1981), our inductive analysis began at the onset of interviewing and concluded after all data were collected. Specifically, our team met regularly to: (1) review the data that had been collected to date and identify preliminary themes or categories that were emerging, (2) revisit categories previously devised and assess their relevance to new data that were collected, (3) create typologies for major categories or themes that emerged, and (4) assess the relationships that surfaced between categories (Goetz \& LeCompte, 1981).

In the first step, data reduction (Lee, Mitchell, \& Sablynski, 1999), the research team met at various stages of the data collection process to identify first-order codes that were emerging in the interview data. First-order coding involves assigning categories to naturally occurring themes in the data; in first-order coding, "the researcher creates as many categories as needed to organize, explain, and assign empirical data to these categories in a coherent fashion" (Lee, 1999: 48). Each researcher read and re-read the interview transcripts and assigned preliminary summary labels to first-order codes. For example, when responding regarding the personal qualities that make followers more or less effective, participants suggested that being positive, having a good attitude, avoiding negativity, and looking on the bright side were all characteristics that a follower needed to be effective. The first-order theme for this group of responses was labeled "positive at- 
titude." This process was repeated until enough first-order labels were obtained to sufficiently account for themes across the data (Miles \& Huberman, 1994). Once summary labels were generated for all categories, these labels were subsequently used to code all interview data (see summary labels and definitions for first-order codes in Table 1).

After devising first-order summary labels, the degree of support for each code was gauged by calculating coding frequencies (i.e., the number of times that a particular code was mentioned within and across interviews; Lee et al., 1999). Several researchers suggest that a minimum frequency be determined such that any code category that has a code frequency below the minimum is deleted from further analysis (Anderson, 2007). In this study, a code was assumed to have sufficient support if it generated a coding frequency that was greater than six. This process yielded a final coding scheme with 12 first-order categories that describe the personal qualities and behaviors that respondents identified as leading to follower effectiveness and 4 first-order categories that describe salient contextual influences (see Table 1).

In addition to assigning first-order codes to the data, consistent with (Campbell and Martinko, 1998) and (Lee et al., 1999), ratings of follower passivity/activity were also assigned case-by-case based on the interview responses of each participant. This scoring method is conducted at the participant-level of analysis (rather than the paragraph or sentence level), and is effective in summarizing data across a number of respondents (Lee et al., 1999). A Likert-type rating scale ranging from 1 (passive follower) to 5 (proactive follower) was assigned to each interview by four independent coders. Cohen's (1960) measure for inter-rater reliability was computed across these ratings and yielded an acceptable reliability coefficient of .78.

Once agreement was reached among the research team on coding (the coding categories, first-order summary labels, and Likert-scale ratings of passivity/proactivity), the entire coding process was replicated by two independent coders who were not involved in inductive processes used to create the coding scheme. The independent coders were trained to understand the interview protocol and the coding categories, and were instructed to code at the paragraph level of analysis (Miles \& Huberman, 1994). Coding at the paragraph level of analysis safeguards against over-inflation of code frequencies by ensuring that repeated themes emerging from a respondent's answer to a single question are not coded more than once. The independent coders met frequently with researchers to clarify the coding process and assess agreement levels. When disagreements occurred, the coders were asked to discuss the reasons for their disagreement and correct problems of interpretation or code definitions. Final codes were entered into Atlas/Ti, a code-and-retrieve software program, and analyzed to obtain frequencies of major themes. Inter-rater reliability among the coders resulted in an adequate reliability coefficient of .93 .

In the results that follow, we highlight the social constructions of followership that were revealed by our respondents. We also drill down to uncover the followership schema that lie at the heart of these social constructions (i.e., beliefs about

Table 1. Coding categories and definitions for major coding categories.

\begin{tabular}{|c|c|}
\hline Code & Definition \\
\hline \multicolumn{2}{|c|}{ Coding categories for prototypical personal qualities and behaviors } \\
\hline Team player & Willingness to work in cooperation with others. Emphasizing collective effort and cooperation. \\
\hline Positive attitude & $\begin{array}{l}\text { Individual is inclined to approve, help, or support. Emphasizing what is laudable, hopeful, or } \\
\text { good. }\end{array}$ \\
\hline Initiative/proactive behavior & $\begin{array}{l}\text { Willingness to identify, confront, and solve problems or issues; recognize and act on initiatives } \\
\text { without deferring to the leader. }\end{array}$ \\
\hline Expressing opinions & $\begin{array}{l}\text { Individual makes known his/her opinions and feelings to the leader and the group. Construc- } \\
\text { tively challenges leader's ideas, decisions, initiatives, etc. }\end{array}$ \\
\hline Flexibility/openness & Willingness to adapt to and be malleable. Open to new ideas or experiences \\
\hline Obedience/deference & $\begin{array}{l}\text { Not participating readily or actively. Not involving visible reaction or active participation. Go- } \\
\text { ing along with others; Submitting without resistance. }\end{array}$ \\
\hline Communication skills & $\begin{array}{l}\text { Able to exchange ideas and thoughts. Understanding audience and framing arguments } \\
\text { accordingly. }\end{array}$ \\
\hline Loyalty/support & Faithful adherence to the leader and support for his/her ideas. \\
\hline Responsible/dependable & Capable of being depended on; worthy of trust; reliable \\
\hline Taking ownership & $\begin{array}{l}\text { Emphasis on taking full responsibility for, and having power and influence over, any part of } \\
\text { an individual's job. }\end{array}$ \\
\hline Mission conscience & $\begin{array}{l}\text { Being mindful of the overarching company goals and direction. Focusing on the bigger picture } \\
\text { and greater purpose of the work. }\end{array}$ \\
\hline Integrity & Adherence to moral and ethical principles; soundness of moral character; honesty \\
\hline
\end{tabular}

Coding categories for contextual themes Hierarchical/bureaucratic work context Empowering work climate

Authoritarian leadership

Empowering/supportive leadership
Emphasize a command and control working relationships. Operate in a top-down fashion. Shared perception that the organization encourages individuals to be proactive and get involved in decision making.

Leadership characterized by an insistence on obedience and authority.

Provide autonomy and encouragement to followers. Share information to build efficacy and strengthen follower performance. 
the personal qualities and behaviors that make followers effective) and the contextual variables that influence followership constructions and behavior. Throughout this discussion, we compare coding patterns across individuals with divergent social constructions.

\section{Results}

Given that previous research has found multiplicity of meaning within social constructions of leadership (Bresnen, 1995), we expected that individuals would also show variations in their socially constructed definition of followership. Supporting this expectation, analysis across participants' responses revealed differentiation between socially constructed definitions of the follower role. More specifically, some followers defined their role around passivity, obedience, and deference, while others saw their role as largely proactive and participative.

\subsection{Social constructions: passive, active and proactive}

\subsubsection{Passive constructions}

Just over one-third $(39 \%, n=12)$ of the respondents revealed socially constructed definitions that were strongly aligned with traditional, passive descriptions of followers. For example, when asked what followership meant to them, these respondents said:

"Mostly following orders. Following through and carrying out orders. Making sure that things get done. Basically to support the leaders and their decisions and do things that way." (Organizational Position: Dental Assistant)

"As a subordinate, it takes a person who is really willing to listen and follow, which is a difficult thing. Especially since you may not be privy to all the information, so in that way, you can't question everything, you just have to go with it. If a leader says we have to go with that, we go with that." (Organizational Position: Administrative Coordinator)

This group of respondents saw the follower role as inherently more passive and identified the importance of following through, taking orders, and doing things the "leader's way." In addition, individuals with passive social constructions emphasized the relative lack of responsibility that is associated with the follower role and placed heavy emphasis on the importance of deferring to the leader's knowledge and expertise. For example, when talking about the benefits of being in a follower role, one respondent put it this way:

"I like that there is no responsibility or minimum responsibility. You don't worry about the job when you go home, and there's just the freedom that comes from that lack of stress. [Managers] have to manage the other staff, and some of them are very difficult." (Organizational Position: Food Server)

\subsubsection{Active constructions}

In contrast, another group $(32 \%, n=10)$ of respondents revealed more active social constructions of followership by emphasizing the importance of expressing their opinions and offering input when it was solicited by their leaders. Followers with active social constructions also suggested that leaders have greater expertise and knowledge to make decisions, however they placed some importance on the contribution that they make to the leadership process. When asked what followership means to them, these respondents said the following:

"It seems to me that many times, the knowledge that [leaders] have, working with different ideas and different concepts, different mandates, different financial knowledge that they have; a lot of decisions have to be made there. I would say that I'm often times given the opportunity to voice ideas or concerns. But when the final decision has to be made...many times I feel like I'm more in a follower position." (Organizational Position: School Principal)

"I would say it's my leader giving me direction, but also me giving him direction. I give him updates on what we are doing... and if he sees strategic things happening in a different direction, then I would be expected to change my plans, move around, and do whatever is necessary to incorporate his ideas." (Organizational Position: Editor of Financial Systems)

These quotes highlight the importance of offering opinions, but remaining loyal and steadfast to a leader's decisions. In contrast to followers with passive social constructions who saw reduced responsibility as an advantage of being in a follower role, participants who viewed the follower role as more active emphasized the advantages of being able to learn from people in leadership positions. For example, one respondent stated:

"I think in a subordinate position, you have a chance to learn, you have a chance to see things from a subordinate position that, sometimes when you're on the 'perch,' you don't necessarily see." (Organizational Position: School Principal)

\subsubsection{Proactive constructions}

A third group of respondents $(29 \%, n=9)$ revealed a more proactive social construction characterized by taking initiative, offering feedback and advice to leaders, and constructively challenging their leaders' assumptions before they were 
asked to do so. This group of followers talked candidly about the importance of influencing leaders' decisions and questioning their directives. When asked what followership meant to them, these participants responded with the following:

"To me, to be an effective follower is all about being proactive. Doing some of the detailed thinking that your leader may not. But the other important thing of an effective follower is when to say no. When to bring other valid information to the table that says, you know what? Let's talk about what you're trying to achieve rather than the solution you are asking me to implement. So saying no and challenging the thinking of that person you are following." (Organizational Position: Insurance Manager)

"I'm more like a quiet leader. I basically let my director know that there are things that I can make decisions on, but things that also need to be his decision. So, we had a meeting about a month ago and we agreed that he has enough trust in me that I will make the right calls for the right reasons. So I am going to take more of a leadership role going forward." (Organizational Position: IT employee)

"I am a subordinate. I have no direct reports, so I have no direct influence over anybody. So I have to gain [my leaders'] respect, gain the power to influence them to accomplish the goals that I feel are necessary for [my] programs. People aren't just going to arbitrarily listen to what I have to say." (Organizational Position: Program Manager, Product Development)

As demonstrated above, followers with proactive social constructions emphasized the importance of influence, challenge, and "silent leadership" when enacting the follower role. This is in contrast to the group of passive followers who placed greater salience on deference and doing things the "leader's way." Indeed, followers who saw their role as more proactive expressed the importance of offering unsolicited feedback or advice and influencing leaders to weigh alternative perspectives. One particularly interesting finding is that the themes identified as a benefit for respondents with passive social constructions (e.g., reduced responsibility) were identified as a drawback for the respondents with proactive social constructions. For example, one participant stated:

"I like to get things done, I'm an action oriented person, and when you're in a subordinate role, sometimes you can't force the action the way you want it to go... and that is probably a drawback of being a subordinate. Most of the people who are subordinates would prefer not to deal with the responsibility or accountability more than they would prefer to be a change agent." (Organizational Position: School Principal)

\subsubsection{Summary}

Overall, participants' responses showed that followers socially constructed their role around the levels of passivity or proactivity they believed followers should display. For example, the responses of the more passive followers highlighted themes of reduced responsibility and decision making, as well as a lack of stress that they frequently associated with the leadership role. Proactive followers, on the other hand, expressed the desire to take ownership and accountability, and highlighted problems and frustration associated with not always having the authority to drive an issue in the direction they perceived was best for their department or organization. On the continuum between passive and proactive followers, individuals who conceptualized followership as an active role wanted input in decisions, but only expressed their opinions when given the opportunity. This emerged as a major difference between those followers who revealed a proactive social construction and those who revealed an active social construction.

\subsubsection{Additional analyses}

To consider whether responses varied across organizational level or industry, we checked for varying patterns of relationships in reports of social constructions across these variables. No significant relationships were found in our sam-

Table 2. Number of participants in various levels and industries by social construction classification.

\begin{tabular}{|c|c|c|c|c|}
\hline & Passive & Active & Proactive & Total \\
\hline \multicolumn{5}{|l|}{ Organizational level } \\
\hline Non-supervisory & 6 & 6 & 3 & 15 \\
\hline Supervisory & 4 & 1 & 3 & 8 \\
\hline Middle management & 2 & 3 & 3 & 8 \\
\hline \multicolumn{5}{|l|}{ Industry } \\
\hline Education (K-12) & 2 & 3 & 2 & 7 \\
\hline Education (college level) & 2 & 4 & 0 & 6 \\
\hline Health care & 2 & 0 & 1 & 3 \\
\hline Hi-technology & 1 & 0 & 1 & 2 \\
\hline Consulting & 1 & 2 & 0 & 3 \\
\hline Media & 0 & 1 & 2 & 3 \\
\hline Financial services & 2 & 0 & 1 & 3 \\
\hline Government & 1 & 0 & 2 & 3 \\
\hline Other & 1 & 0 & 0 & 1 \\
\hline
\end{tabular}

Numbers in each cell represent the number of participants. 
ple. Individuals with passive, active, and proactive social constructions appeared to be evenly dispersed across organizational levels and industries (see Table 2).

Given that social constructions are a product of both individual schema and contextual influences, our next step in the analysis was to understand the followership schema that underlie passive, active, and proactive social constructions. Followers were placed into "passive," "active," or "proactive" groups based on the participant-level rating that was assigned to them in the coding process. For the purpose of exploration, and to achieve cross-category comparisons, themes regarding prototypical follower traits and behaviors were analyzed by calculating frequencies within each of the passive, active, and proactive follower groupings (see Table 3). Coding of followership prototypes revealed 12 categories of personal qualities/behaviors that were salient to the follower role. However, an evaluation of coding frequencies across the passive, active, and proactive follower groups revealed coding differences in only a few coding categories. We present these results below, and provide coding frequencies and sample quotes for all coding categories regarding personal qualities and behaviors that reportedly lead to follower effectiveness in Table 3.

\subsection{Personal qualities and behaviors identified by passive followers}

The twelve respondents who revealed a passive social construction of followership were grouped together under the term "passive followers" and their responses were analyzed to understand salient followership prototypes. When exploring their followership schema (i.e., questions about the personal qualities and behaviors that make followers effective), this group revealed themes that strongly aligned with traditional conceptualizations of obedience and deference. For example, passive followers highlighted personal qualities and behaviors such as having the ability to be flexible and open to change $(n=7)$, having a positive attitude $(n=10)$, and being obedient $(n=13)$ with greater frequency than the active or proactive followers (see Table 3). For example, one respondent highlighted the importance of being obedient and not making waves:

"The more successful subordinate, you know, [it's] a much more passive role. Non-confrontational. Not a risk taker. A less successful subordinate is if you're the assertive type of person, you wanna take charge of things, you always want to be in control... Non-confrontational people I've encountered seem to get along a lot better, be more adaptable... They go with the flow, they are much more flexible in situations than other people." (Organizational Position: School Principal)

The passive behaviors identified above were very salient to this group of respondents, and overall, it was clear they saw a successful follower as someone who did not question authority or actively disagree with the status quo. Furthermore, many of the respondents mentioned that challenging the status quo was a behavior that contributed to ineffective followership. For example, one respondent stated the following:

"I can think back to an incident several years ago at our school...our superintendent was having some problems with a veteran teacher here, and had come to the conclusion that this teacher needed to make some changes or he wasn't going to be asked back...The teacher didn't follow instructions that were given by the superintendent and by me and by our board of education... actually, basically did just the opposite of what he was asked to do....and while I

Table 3. Sample quotes and coding frequencies for prototypical personal qualities and behaviors.

\begin{tabular}{|c|c|c|c|c|c|}
\hline Code & Sample quote & Passive & Active & Proactive & Total \\
\hline Team player & $\begin{array}{l}\text { "I don't care if it's the lowest position or the highest, if you } \\
\text { are not a team player, you will not be effective." }\end{array}$ & 8 & 9 & 7 & 24 \\
\hline Positive attitude & $\begin{array}{l}\text { "Subordinates who are gonna be successful are those that } \\
\text { enjoy what they do and have a positive attitude." }\end{array}$ & 10 & 8 & 5 & 23 \\
\hline Initiative/proactive behavior & $\begin{array}{l}\text { "I generally tend to propose something that I see needs to } \\
\text { be done, so it's not solicited." }\end{array}$ & 1 & 8 & 13 & 22 \\
\hline Expressing opinions & $\begin{array}{l}\text { "I raise the issue and the awareness...last year, I raised the } \\
\text { issue that we needed to manage global security issues." }\end{array}$ & 2 & 6 & 14 & 22 \\
\hline Obedience/deference & $\begin{array}{l}\text { "It takes a person who is willing to listen and follow... you may } \\
\text { not be privy to information so you just have to go with it." }\end{array}$ & ay 13 & 8 & 1 & 22 \\
\hline Flexibility/openness & $\begin{array}{l}\text { "I think you have to be flexible. I think you have to be willing } \\
\text { to accept change." }\end{array}$ & 7 & 5 & 7 & 19 \\
\hline Communication skills & $\begin{array}{l}\text { "I think the most important thing for a follower is } \\
\text { communication." }\end{array}$ & 4 & 5 & 8 & 17 \\
\hline Loyalty/support & $\begin{array}{l}\text { "You have to respect the people above you and be loyal... } \\
\text { the decision's been made, I'm gonna accept it." }\end{array}$ & 3 & 4 & 2 & 9 \\
\hline Responsible/dependable & $\begin{array}{l}\text { "I have to prove that I am responsible, that I } \\
\text { can handle situations on my own." }\end{array}$ & 3 & 3 & 3 & 9 \\
\hline Taking ownership & $\begin{array}{l}\text { "We took ownership over our different sections and did } \\
\text { whatever necessary to make it work." }\end{array}$ & 1 & 3 & 5 & 9 \\
\hline Mission conscience & $\begin{array}{l}\text { "Good followers try to see the big picture and see what's } \\
\text { gonna be best for the organization." }\end{array}$ & 2 & 3 & 3 & 8 \\
\hline Integrity & $\begin{array}{l}\text { "Honesty is right up there. I can work with a person that } \\
\text { says, 'ah man, I screwed up.'" }\end{array}$ & 3 & 3 & 1 & 7 \\
\hline
\end{tabular}


was not directly involved in the observations, I did make some, and was able to corroborate with our superintendent and, again while serving in that subordinate role, agree with what he had seen. And I guess the successful part was that we got what we feel was a better teacher in that position." (Organizational Position: School Principal)

Overall, this more passive group of participants spoke very candidly about the passivity of the follower role. Specifically, this group differed from the rest of the participants in that they were less willing to speak out and take risks, and they were primarily interested in showing their supervisors loyalty and support.

\subsection{Personal qualities and behaviors identified by active followers}

The ten respondents who revealed an active social construction were grouped together and classified as "active followers." When asked about the personal qualities and behaviors that make followers effective in their role, active followers highlighted themes regarding ownership $(n=3)$, offering opinions $(n=6)$, and being a team player $(n=9)$. In addition, they placed less emphasis on the importance of being deferent and obedient $(n=8)$ than individuals identified as passive followers. For example, one respondent mentioned, “I don't care for people who sit there and just say, 'I don't know, it wasn't my decision, I'm just following.' I don't mind taking the buck if I know why, and let people get angry at me if they are not happy."

With regard to taking ownership, one participant described a situation wherein a follower refused to take ownership for a failed banking deal, and left others to pick up the pieces:

"A classic example is from my commercial banking days; a deal goes sideways, and the individual washes their hands of it and says 'it isn't my deal.' Yeah, it's a \$10 million transaction, but they don't wanna take ownership for it, and then you're left scrambling trying to fix it...and you've lost the customer because they're ticked off." (Organizational Position: Associate Director, Career Management Services)

In addition to taking ownership, active followers also mentioned that being able to voice their opinions at the appropriate time and in a positive manner was essential for follower success. In contrast to the passive followers who mentioned that they rarely voiced their opinions, active followers mentioned that they were regularly given the opportunity to express concerns. However, similar to passive followers, active followers also emphasized the importance of supporting a leader's decision regardless of whether they personally agreed with it:

"I think that our central administration does a great job of listening and letting us be heard. I can think of a recent example with the hiring of a para-educator...I got a chance to be heard when those decisions were made, and really were not exactly the way I wanted them to go. I guess I look at it this way...I can take that and I can do two things: I can accept it, I can be respectful, I can be loyal, I can work out ways to make it work, or I can complain about it, and be deceitful, I can say bad things about the decision... and I think that sets a tone for the whole building." (Organizational Position: School Principal)

\subsection{Personal qualities and behaviors identified by proactive followers}

The nine respondents who revealed a proactive social construction of followership were grouped together and classified as "proactive followers." The personal qualities and behaviors that lead to success in the eyes of proactive followers were similar to those identified by active followers, only they were mentioned with greater frequency. Like active followers, proactive followers perceived that taking ownership $(n=5)$, offering opinions $(n=14)$, and taking initiative $(n=13)$ were all behaviors that made them effective in their follower role. Additionally, while active followers mentioned obedience with less frequency than passive followers ( $n=8$ vs. $n=13$, respectively), proactive followers mentioned obedience only once. Thus, this theme of obedience and deference, which is commonly associated with the role of a follower, was of little salience to proactive followers.

With regard to offering opinions and taking initiative, proactive followers were quick to mention that they took opportunities to voice their concerns and offer solutions to problems before being asked to do so by their leaders. These individuals also tended to go out of their way to divert crises without the fear of reprisal from their leaders. For example, after proactively making a decision regarding the best way to handle a student athlete with a negative attitude, one principal elaborated on the reactions he received from his superintendent:

"The assistant principal made the decision, and I supported him. But the superintendent wanted her to be suspended for 2 or 3 games... we didn't feel that this really warranted that. And, as is usually the case, the superintendent calls me in, and I explained why the decision was made... and I told him, we had no proof that she even said those things... should I just go ahead and suspend her right there or should I check into it and find out if its valid." (Organizational Position: School Principal)

Another respondent mentioned that on at least one occasion, he had confronted his leader on her negative attitude and demeaning behavior that was exhibited in front of their team:

"I noticed that she made some comments in front of the team: 'Geez, they shouldn't have done that.' So when I had a chance to meet with her, I said, 'I don't know if this is going to get me fired, but I see that we have some issues with 
building the team, so as a result, I don't think it's a good idea for you to criticize the other team members in front of your own team... and I understand that you feel like you are part of them, but you are managing [both teams] now and you may need to set the right tone.'" (Organizational Position: IT employee)

Essentially, the proactive followers were demonstrating behaviors that are traditionally associated with leadership, rather than followership. In addition, many of these respondents condemned the blind obedience and unquestioning behaviors of others. For example, one respondent put it this way:

"I notice that a lot of followers just tend to take little steps...they just listen to the higher up and say, 'whatever you say, I'll do.' They're trying not to rock the boat. And what I am disappointed about is, how is that really helping the company in the long run?" (Organizational Position: IT employee).

\subsection{Contextual influences on followership constructions and behavior}

As mentioned earlier, social constructions can be influenced by contextual variables, including leadership style and organizational climate. Therefore, we also examined the data relative to contextual variables of leadership and climate and their potential influences on followership constructions and behavior.

\subsubsection{Leadership themes}

In our data, respondents spoke about leadership style as a contextual variable that influenced their definition of followership and the way they behaved in the follower role (see Table 4). For example, when juxtaposing the leadership style of their current manager with that of previous managers, several respondents spoke about the benefits or drawbacks of working with leaders who displayed various styles:

"Before my current director, I had another director. She was a bit more supportive in the sense that she gave you enough room to run. She allows you to understand what the goals are... as long as you're heading in the right direction, she was fine with that. My current manager doesn't do that as often. Even though he gives a lot of freedom, he tends to be a bit more hands on...that provides a big challenge for us." (Organizational Position: IT employee)

This quote highlights the important role that context plays in followership constructions and behavior and suggests that social constructions may be somewhat dependent on the style of a particular leader. Such leadership themes generally emerged around the way that authoritarian or empowering leaders influence definitions of the follower role. For example, several respondents spoke candidly about their leader's authoritarian style and overall tendency to snuff followers' attempts to take initiative or demonstrate their own leadership ability $(n=13)$.

"In this rural district, there are only two administrators, myself and the superintendent. We're in the same building... basically across the hall. So he has made it very clear that it is his building, his staff, his kids. And while I have a good working relationship with him, most definitely it is apparent that he is the leader." (Organizational Position: School Principal)

Whereas authoritarian leadership style emerged as a major contextual theme, several respondents also spoke about their leader's effort to share power and decision making $(n=14)$ :

"My direct supervisor is not particularly directive in my role, although certainly he has his opinions and he voices them and we discuss them, and then we decide where to go from that point. But I use him more as a sounding

board." (Organizational Position: Manager of Responsible Care)

Table 4. Sample quotes and coding frequencies for contextual variables.

\begin{tabular}{|c|c|c|c|c|c|}
\hline Code & Sample quote & Passive & Active & Proactive & Total \\
\hline Empowering/supportive leadership & $\begin{array}{l}\text { "Our superintendent wants us to take owner- } \\
\text { ship and he just feels very comfortable sharing } \\
\text { decision making and empowering us." }\end{array}$ & 3 & 7 & 4 & 14 \\
\hline Authoritarian leadership & $\begin{array}{l}\text { "[My manager] definitely treated us as if we } \\
\text { didn't have any brains and as if we were } \\
\text { children and couldn't think for ourselves. She } \\
\text { over-managed us." }\end{array}$ & 3 & 4 & 6 & 13 \\
\hline $\begin{array}{l}\text { Hierarchical/bureaucratic } \\
\text { work context }\end{array}$ & $\begin{array}{l}\text { "The culture of the company is just something } \\
\text { that's almost mechanical. I think that employees } \\
\text { start to lose that zest; that kind of impetus to go } \\
\text { the extra mile." }\end{array}$ & 2 & 3 & 4 & 9 \\
\hline Empowering work climate & $\begin{array}{l}\text { "Our organization is pretty flat...so we have } \\
\text { a great deal of autonomy in decision making." }\end{array}$ & 2 & 2 & 3 & 7 \\
\hline
\end{tabular}


Through the process of evaluating leadership themes across individuals with passive, active, and proactive social constructions, it was clear that active and proactive followers found it most difficult to work with authoritarian leaders $(n=10)$. For example, several respondents spoke candidly about how leaders discouraged followers from speaking up.

"One thing that happens here a lot is that we have very vocal executives that shoot down a lot of people when they're speaking their minds. So, in turn, a lot of people don't speak their minds when they should. They're really the follower type that just say 'well, I better not say anything or else I'll have my head bitten off.'" (Organizational Position: Program manager).

"I was still new... and I had some ideas about changing our administrative structure here and started talking to people to get information. I had not been asked to change it...I did it on my own. And a few days later, our superintendent comes up to me and says 'I heard you were thinking about us' ... and he really didn't care for my thought process or what I had to say. It was a sobering experience" (Organizational Position: School Principal)

As noted above, these respondents suggested that they had to shift their definition of followership so that their behavior was appropriate for the context. For example, one respondent elaborated on how his followership schema is more proactive in nature, but given his leader's authoritarian style, he was forced to construct followership around more active (rather than proactive) behavior:

"I'm a rather poor subordinate because I have this real drive to be that proactive person. I would love nothing more than to propel [my company] through my own personal qualities and personal drive. Yet, my boss has issues with strong personalities, or feels insecurities in regard to his position. So I play the role. I can always be counted on to give high quality when asked. I am a reliable resource, not so much for affecting wholesale change in the company, but when my talents and abilities are needed, I am there to give them" (Organizational Position: Magazine Editor).

The quote above highlights the role that both schema and context play in followership constructions and behavior. Specifically, this respondent maintained an active construction of followership (e.g., offering opinions when asked) because the context did not allow him to fully engage in proactive behavior. Indeed, several respondents who were classified as proactive followers mentioned that the context forced them to rethink followership, and as a result, many believed that they were not successful because their schema did not match the context within their organization:

"I like to be proactive. And sometimes in a subordinate position, that's not the role you need to play. I think to be a more successful subordinate, I need to learn what my role is, and just do my role and don't do anything more unless I'm asked to do more. And that's something that I continue to struggle with. So, that's why I think most of the time I'm probably not very successful at being a subordinate." (Organizational Position: School Principal).

Conversely, passive followers rarely spoke about the way that their leader's style influenced constructions of followership or behavior in the follower role (authoritarian leadership $n=3$; empowering leadership $n=3$ ). There was, however, one exception to this pattern which was revealed by a passive follower who expressed concern over working with an empowering leader:

"Our superintendent puts us in that leadership role, even though we are subordinates. He trusts us...and feels very comfortable sharing decision making and empowering us. I have always resisted that kind of a position, but overall, I'm happy." (Organizational Position: School Principal)

\subsubsection{Organizational climate themes}

Respondents also mentioned how characteristics of their organization's climate or structure influenced their construction of followership and their behavior in the follower role. Specifically, some respondents spoke about the difficulty they had navigating through bureaucracy or continuing to make a contribution under hierarchies of authority $(n=9)$.

"The organization I came from prior to this was much larger. I had a lot more autonomy to make decisions and I had signing authority for a lot higher dollars than I do in my current role...I have zero signing authority. Everything has to go through the director. I think that's been a downfall of our structure. People either aren't able to, or aren't willing to make decisions. So we get caught up in this loop sometimes where a decision doesn't get made because someone needs to defer to somebody else." (Organizational Position: Program Manager, Product Development)

Others, commented on how an empowering climate and flatter organizational structure made it easy for them to contribute in a meaningful way $(n=7)$.

"We have a fairly flat organization. So I have a lot of autonomy and the opportunity to make decisions and decide how work gets done." (Organizational Position: Manager of Responsible Care)

Similar to our findings on authoritarian leadership, active and proactive followers were the most vocal regarding the constraining effects that bureaucracy and hierarchies of authority can have on the ability to be proactive $(n=7)$. 
"[My manager] and I always have a good laugh about the bureaucracy...you know, the ten signatures that are required to occasionally get things done. And because of that, you have people saying 'This is not my job, that is not my responsibility.' And I've always believed that you may have a job description that says 'Thou shall not do this after 4 pm,' but the reality is, we need to get this done." (Organizational Position: Associate Director, Career Management Services)

Taken together, the quotes above suggest that individuals with active and proactive schema had the most difficulty operating in bureaucratic environments or under authoritarian leaders, and many were forced to construct their follower role around the behaviors that were appropriate for the context. Surprisingly, passive followers rarely spoke about working in an empowering climate or with leaders who encouraged participation (i.e., contextual themes that would not match a passive construction). Indeed, the majority of our context coding involved statements regarding the contextual influences that challenge active or proactive followership schema or made it difficult to act in the way that these followers perceived they should.

\subsection{Summary}

In sum, the findings of our exploratory study suggest that the follower role is more complex and multifaceted than previously thought. Our findings revealed an important link between followership schema, social constructions, and the role that context plays in followership behavior. Specifically, the findings of this study suggest that:

- Participants revealed socially constructed definitions of followership that were passive, active, or proactive in nature. For example, the responses of the more passive followers highlighted the importance of doing things the "leader's way," whereas proactive followers expressed the desire take ownership and accountability.

- On the continuum between passive and proactive followers, individuals who conceptualized followership as an active role wanted input in decisions, but only expressed their opinions when given the opportunity.

- With regard to followership schema, passive followers emphasized the importance of obedience and deference, whereas active and proactive followers emphasized the importance of constructively challenging their leaders and voicing ideas or concerns. Moreover, proactive followers identified blind obedience as a behavior that was associated with ineffective followership.

- Followers spoke about the important role that leadership styles and organizational climate play in their ability to act in alignment with their active and proactive followership schema. Specifically, active and proactive followers spoke about the difficulty working with authoritarian leaders or in hierarchies of authority, whereas passive followers rarely spoke about the impact that contextual variables had on their followership role.

\section{Discussion}

The purpose of this study was to deconstruct the meaning of followership by investigating how individuals socially construct follower roles in organizations. We also set out to identify the personal qualities and behaviors that individuals believe are important to success as a follower (followership schema), and contextual variables that affect followership constructions and behavior. In line with Shamir's (2007) call to "reverse the lenses," this study takes a first step toward understanding how followers define their roles in relation to organizational leaders-i.e., how followers define followership.

Based on our findings, it appears that followership constructions exist along passive, active, and proactive dimensions (Kelley, 1992). Followers who were identified as holding a passive social construction emphasized the importance of taking and following orders, deferring to the leader's knowledge and expertise, and remaining loyal to and supportive of the leader's initiatives. This conception, which is consistent with Uhl-Bien and Pillai's (2007) writings on the subordination of followership, may be a product of the socialized tendency to obey authority figures (Blass, 2000; Milgram, 1965) and attribute power and status to individuals in advanced hierarchical positions (Berger et al., 2002; Hecksher, 1994; Morand, 1996). Indeed, many of our respondents identified their leaders as having the required knowledge and expertise to make decisions and chart the future direction of their company.

Respondents who possessed an active social construction defined their role in terms of offering opinions when given the opportunity, but remaining obedient and loyal regardless of whether they were in agreement with the actions of the leader. In line with research on mutual influence (Greene, 1975; Lowin and Craig, 1968) respondents with active social constructions emphasized the importance of speaking up, offering opinions, and "giving their leaders direction." However, like the more passive followers, active followers expressed the importance of remaining loyal to their leaders and always maintaining a positive attitude. They were not willing to "push the envelope," so to speak, or constructively challenge their leader's actions. This finding supports previous research suggesting that followers may refrain from overtly challenging their leaders for fear of violating social norms (Courpasson \& Dany, 2003) or damaging relationships with their leaders (Glauser, 1984; Milliken et al., 2003; Tynan, 2005). Overall, it appears that active followers were responsive to their leaders' requests, but lacked the self-initiating behavior to proactively identify a need and respond to it without a direct request from their leader.

Finally, followers who revealed a proactive social construction identified behaviors more aligned with partnership relationships (Uhl-Bien et al., 2000) than those based on dominance and submission (Courpasson and Dany, 2003; Tyler, 1997; Wortman, 1982). Proactive followers saw themselves as active participants - or co-producers (Shamir, 2007) - in the leadership process; they viewed their role as working to advance the mission of their department or organization. In enacting this role, they reported being "quiet leaders," willing to constructively challenge their managers if needed. 
This finding is in line with Sorenson and Hickman's notion of "invisible leadership" (Hickman, 2004), in which individuals are motivated to take action by a commitment to achieve a common purpose without regard for personal recognition, visibility or self-interest. It is also consistent with Bennis' (2000) suggestion that leaders can no longer be considered the most knowledgeable or capable individuals in organizations. Followers who recognize a leader's flawed thinking and challenge the leader to consider alternative courses of action to prevent them from making mistakes or harmful decisions are highly desirable in today's organizational environments (Chaleff, 1995; Hirschhorn, 1990; Morrison and Phelps, 1999). In our sample, proactive followers frequently criticized the passive, obedient behaviors that are typically associated with the follower role. This is not to suggest that proactive followers were disobedient. On the contrary, proactive followers spoke about the importance of constructively questioning and challenging their leaders - rather than blindly following the directives from above-because they were concerned with meeting the mission of the organization.

With regard to differences in follower personal qualities and behaviors, the largest disparity across groups involved themes of obedience, expressing opinions, and taking initiative. The strong relationship between the themes described above and the variations in socially constructed definitions of followership reinforce the notion that constructions are heavily based on individual schema (Meindl, 1995; Weick, 1993). These findings provide evidence that individuals maintain followership schema regarding how they should act in relation to their leader. Given Bresnen's (1995) propositions regarding the relationship between social constructions and behavior, this finding has important implications for organizations. For example, followers who feel their role is best served by remaining silent and loyal to the leader might refrain from standing up to their leaders' abusive, dangerous, or even illegal behavior. Indeed, the recent ethical scandals of the past decade point to examples where followers silently stood by while their leaders defrauded the organization (UhlBien \& Carsten, 2007). On the other hand, followers who are proactive about voicing their concerns may face negative ramifications if the organization's culture does not support such behavior. For example, research suggests that followers may face retaliation if they speak out against their leaders or organizations (Near \& Jensen, 1983).

The findings also provide evidence that social constructions of followership, and the ability to act in alignment with followership schema, may be dependent on the context that is created by the leader and the organization. Participants spoke candidly about the effects that various leadership styles (e.g., authoritarian or empowering) had on the way they constructed followership and their ability to be proactive in the follower role. Several followers commented on how strong bureaucracy diminished their ability to take initiative and move things forward, while others commented on how an empowering climate encouraged them to offer ideas and opinions. These findings are consistent with vast amounts of previous research showing that leadership effectiveness is highly dependent on the organizational context (e.g., Porter \& McLaughlin, 2006). However, one particularly interesting result concerned the followers who defined themselves as "ineffective" because their followership schema did not match the context in which they operated. This finding suggests that, at least in some cases, followers experience conflict between how they believe they should act (i.e., what their schemas and scripts depict as good followership), and the behaviors that are considered acceptable by their leaders and their organizations. This is a very interesting avenue for future research given that we know little about the interaction between schema and context in determining followership behaviors and their attitudes relative to these behaviors.

Based on the design of this study, we cannot draw firm conclusions regarding how passive or proactive followers deal with organizational constraints or the strength of the interaction between followership schema and leadership or organizational context. However, our findings do raise interesting questions regarding these potentially interactive effects. For example, how do individuals respond when their schema are inconsistent with the context, and what is the effect of this response on their feelings about their work situation (e.g., stress, intentions to quit and satisfaction/dissatisfaction)? Are there individual differences such as proactive personality or need for social approval that influence how individuals choose to respond? Under what circumstances do individuals act consistent with their beliefs about their role responsibilities even though the context does not overtly support their actions? What are the consequences of acting out of alignment with the social context, and are these consequences worse for individuals with proactive schema acting in authoritarian environments than individuals with passive schema acting in empowering climates?

Interesting questions also arise regarding the stability of followership schema in changing contexts or environments. Given research suggesting that cognitive structures are fairly stable (Harris, 1994), organizations that implement empowerment initiatives such as self-managed teams might find it difficult to change followership schema that are predominantly passive and deferent in nature. ${ }^{1}$ In these circumstances, the organization may face push-back from followers, and it may be necessary to design and implement training initiatives (Logan \& Ganster, 2007). Followers who believe that it is not their job to lead might wreak havoc on organizations attempting to influence more proactive behaviors. Thus, organizations might consider conducting workforce analyses to understand the steps that will need to be taken to ensure that followers accept the empowerment initiative and engage in the desired behaviors. In addition, organizations may need to place greater emphasis on rewarding proactive followership behavior in an effort to shift the dominant schema that individuals may hold about passive followership.

Another area for future research involves the issue of matches and mismatches between followers' and leaders' constructions of followership. While leadership research has long considered the effect that implicit leadership theories have on follower reactions to leaders (Eden and Leviatan, 1975; Epitropaki and Martin, 2005; Lord and Maher, 1991), it may also be that leaders' and followers' reactions to one another are influenced by their implicit theories of followership. We could imagine that leaders with proactive constructions of followership may become very frustrated by followers who 
act consistent with passive constructions. Alternatively, leaders with passive constructions may view proactive followers as pushy, insubordinate and disrespectful. Passive followers may find it difficult to work with leaders who have a proactive construction of followership. Moreover, proactive followers may find authoritarian leaders "old school" and highly ineffective. In such cases, it would be interesting to examine whether followers would still be proactive with their leaders and/or try to find a style that allows them to influence leaders in an effective way, or would these types of followers subdue their natural tendencies toward proactivity (i.e., adopt a more passive role).

Finally, our findings on proactive followership offer important insights that may have potentially interesting implications for leadership research more broadly. Specifically, proactive followers didn't merely regulate their own behaviors (i.e., self-leadership, Manz, 1986), lead other team members toward a mutual goal (i.e., shared leadership, Pearce \& Conger, 2003), or influence leaders to obtain desired resources (i.e., upward influence, Deluga \& Perry, 1991). Rather, proactive followers actively influenced their leaders through constructive challenge and upward communication in an attempt to advance positive change in their department or organization. While these findings are consistent with Chaleff's (1995) conceptualization of "courageous followership" and Kelley's (1992) typology of "exemplary followers," the descriptions offered by proactive followers appear more consistent with leading than with "following." For example, these individuals do not follow (e.g., conform to, comply with, obey, imitate, go along; dictionary.com); instead, they lead (e.g., influence, advance, contribute, persuade, affect; dictionary.com).

Hence, perhaps these findings offer implications for an "expanded view" of leadership (Hiller, Day, \& Vance, 2006) that goes beyond leading "down" to a concept of leading "up," i.e., leading from a "subordinate" role. In particular, an implication of proactive constructions of followership may be the need to broaden our views of leadership beyond topdown managerial leadership to leadership that can also flow upward in organizations. While this type of upward leadership would obviously be quite different from that occurring in top-down managerial roles, it seems to still be leadership in that it involves using influence to create change toward a common purpose (Bryman, 1996; Hickman, 2004; Rost, 1995). Therefore, just as we have identified extensive typologies of leadership behaviors for top-down (managerial) leadership, the findings reported here suggest that we may also want to consider typologies for leading-up (i.e. upward leadership).

\subsection{Limitations}

Given our exploratory qualitative approach and small sample size, these findings should be interpreted with caution until they have been replicated in a variety of settings and with multiple methodologies. It is important to note that interview data are a subjective reflection of followers' perspectives and experiences, rather than objective accounts of reality. Although this methodology was appropriate for understanding respondents' socially constructed definitions of followership, future research will benefit from multi-method approaches to data collection that examine variations in followership perceptions from individuals at various organizational levels and across industries. Interesting avenues for future research include longitudinal analyses of social constructions to investigate how followers are socialized into particular contexts and whether socialization processes affect changes in followership schema over time (Lord \& Hall, 2003).

Moreover, due to the qualitative method used in this study, we were not able to gather personality measures that could help us understand how individual differences might lead followers to adopt more passive or active social constructions and whether or how these would vary in different situations. Therefore, another worthwhile area for future research is examination of how follower traits relate to followership schema and social constructions under different contextual conditions (e.g., different leadership styles and organizational climates).

Finally, the findings are based on data gathered from a North American sample (U.S. and Canada). It is highly likely that social constructions of followership will vary across cultures. For example, people from individualistic cultures emphasize the benefits of autonomy, personal freedom by way of participation in decision making, decentralized decision making, and employee centered incentive systems (Earley \& Gibson, 1998). Thus, it could be that more individualistic cultures may place greater value on proactive behaviors in a followership role than collectivistic cultures. Similarly, cultures that are high in power distance will tend to have more autocratic styles of leadership in which employees are expected to follow established patterns of communication and be heavily dependent on supervision and the organization for instruction (Erez and Earley, 1987; Hofstede, 1980; Rodrigues, 1990). Such cultures may socialize individuals into a more passive schema of followership emphasizing obedience and deference. Therefore, future research should consider whether and how aspects of cultural values play a role in the creation of schemas of followership and the social construction of followership based on contextual factors of the work environments.

\section{Conclusion}

In seemingly a "mirror image" of Bresnen's (1995) findings regarding social constructions of leadership, the findings of our study reveal that followership holds "a multiplicity of meaning" for individuals occupying the role. Just as Bresnen found that leaders socially construct their roles around more proactive views of being a change agent or more authoritarian views of control over followers, our findings show that individuals hold followership schema along a continuum from more passive (e.g., blindly obedient) to more proactive (e.g., change agent) views. The strength with which these schema influence social constructions in particular workplaces, however, appears to be related to contextual variables of leadership styles (authoritarian or supportive/empowering) and climate (bureaucratic/hierarchical or empowering). Thus, in alignment with propositions by Meindl (1995), social constructions of followership appear to be the product of individual schema and relevant contextual variables that operate in a given organization. 
These findings have important implications with respect to organizations' desire for passivity (e.g., blind obedience and deference) or proactivity (e.g., partnership or co-leadership) among their employees and whether employees' followership schema "fit" with the organization's climate. Moreover, they have implications for leadership research in that they verify the need to "reverse the lenses" by more fully considering the other half of the leadership equation, the enactment of followership, and perhaps even suggest a need to expand views of leadership beyond leading down to leading-up. Taken together, we believe the findings of the present study provide strong support for advancing a call to more actively develop and explore a construct long overlooked in the domain of leadership research: the construct of followership.

\section{Acknowledgments}

The first author would like to thank the Institute for Innovative Leadership and the University of Nebraska for the resources and support needed to complete this project. We would also like to thank Steve Kempster and three anonymous reviewers for comments on an earlier draft of this paper. A version of this paper was presented at the Southern Management Association's annual conference in Nashville, TN.

\section{Appendix A.}

\section{Interview protocol for followership constructions}

The purpose of this study is to investigate how people view their roles in organizations. When answering the interview questions, we would like you to reflect on the hierarchy in your organization and your role as a subordinate. Specifically, we would like you to think about how you interact with the people in positions above you. All responses to these questions will be held strictly confidential and you will not be identified as a participant in this study. In order to accurately capture all of your responses, I would like to ask your permission to tape record the interview. (Start recording) Is it okay if I tape the interview? In addition, would you mind if we used some of your quotes from the interview under an anonymous pseudonym for the purposes of publishing papers or reports?

1. How would you describe your position in the organization? (position, how many subordinates/superiors and role) a. Thinking about your role as a subordinate, what are some of the activities you engage in every week? What kinds of tasks do you work on with your supervisor?

2. Thinking about your role as a subordinate (i.e., working with your current supervisor), to what extent do you see yourself engaging more in leadership or followership-type behaviors?

a. Tell me more about the way you think about followership? What does followership mean to you?

3. Do you think there are benefits of being a follower/subordinate?

a. If yes, what are they?

b. If no, why not?

4. Do you think there are drawbacks to being a follower/subordinate?

a. If yes, what are they?

b. If no, why not?

5. Are there personal qualities AND behaviors that make followers/subordinates more or less successful?

a. If yes, what are they?

b. What outcomes do you think are associated with these characteristics?

6. Tell me about a time when you or someone you know acting as a follower/subordinate engaged in behaviors that resulted in success? (need specifics on the position of the person if they did not use themselves as an example)

a. What happened? (series of events, behaviors, actions, etc.)

b. What were the outcomes?

7. Tell me about a time when you or someone you know acting as a follower/subordinate engaged in behaviors that re-

sulted in FAILURE? (need specifics on the position of the person if they did not use themselves as an example)

a. What happened? (series of events, behaviors, actions, etc.)

b. What were the outcomes?

8. Do you see yourself as a successful follower/subordinate?

a. What makes you successful/unsuccessful?

b. What do others do to make you successful?

c. How do others prevent you from being successful?

9. Have you ever been appreciated for your contribution to your organization/team? a. What was singled out in terms of your contribution?

\section{References}

Allen and Porter, $1983 \varangle$ R. W. Allen and L. W. Porter, eds., Organizational influence processes, Scott Foresman, Glenview, IL (1983).

Anderson, 20074 Anderson, R. (2007). Thematic content analysis (TCA): Descriptive presentation of qualitative data. http://www.wellknowingconsulting.org/publications/pdfs/ThematicContentAnalysis.pdf

Avolio et al., $1996<$ B. J. Avolio, D. I. Jung, W. Murry, and N. Sivasubrimaniam, Building highly developed teams: Focusing on shared leadership process, efficacy, trust, and performance. In: M. M. Beyerlein, D. A. Johnson, and S. T. Beyerlein, eds., Advances in interdisciplinary studies of work teams: Team leadership Vol. 3, Elsevier Science/JAI Press, US (1996), pp. 173-209. 
Bacharach et al., 19954 S. B. Bacharach, P. Bamberger and B. Mundell, Strategic and tactical logics of decision justification: Power and decision criteria in organizations, Human Relations 48 (5) (1995), pp. 467-488.

Baer and Freese, 20034 M. Baer and M. Freese, Innovation is not enough: Climates for initiative and psychological safety, process innovations, and firm performance, Journal of Organizational Behavior 24 (1) (2003), pp. 45-68.

Baker, $2007 \triangleleft$ S. D. Baker, Followership: Theoretical foundation of a contemporary construct, Journal of Leadership and Organizational Studies 14 (1) (2007), pp. 50-60.

Bedeian and Hunt, 20064 A. G. Bedeian and J. G. Hunt, Academic amnesia and vestigial assumptions of our forefathers, The Leadership Quarterly 17 (2) (2006), pp. 190-205.

Bennis, $2000<\mathrm{W}$. Bennis, The end of leadership: Exemplary leadership is impossible without full inclusion, initiatives, and cooperation of followers, Organizational Dynamics 28 (1) (2000), pp. 71-79.

Berger and Luckmann, $1966 \varangle$ P. Berger and T. Luckmann, The social construction of reality: A treatise in the sociology of knowledge, Doubleday, Garden City, NY (1966).

Berger et al., 20024 J. Berger, C. L. Ridgeway and M. Zelditch, Construction of status and referential structure, Sociological Theory 20 (2002), pp. $157-179$

Biggart and Hamilton, $1984 \triangleleft$ N. W. Biggart and G. G. Hamilton, The power of obedience, Administrative Science Quarterly 29 (1984), pp. 540-549.

Bjugstad et al., $2006<\mathrm{K}$. Bjugstad, E. C. Thach, K. J. Thompson, and A. Morris, A fresh look at followership: A model for matching followership and leadership styles, Journal of Behavioral and Applied Management 7 (2006), pp. 304-319.

Blanchard et al., $1999<$ K. H. Blanchard, J. P. Carlos, and W. A. Randolph, The 3 keys to empowerment, Berrett- Koehler Publishers, San Francisco (1999).

Blass, $2000 \triangleleft \mathrm{T}$. Blass, The milgram paradigm after 35 years: Some things we know about obedience to authority. In: T. Blass, ed., Obedience to authority: Current perspectives on the Milgram paradigm, Lawrence Erlbaum, Mahwaw, New Jersey (2000), pp. 35-60.

Blau, $1968<$ P. M. Blau, Hierarchy of authority in organizations, The American Journal of Sociology 73 (4) (1968), pp. 453-467.

Bligh et al., $2007 \triangleleft$ M. C. Bligh, J. C. Kohles, C. L. Pearce, J. E. Justin, and J. F. Stovall, When the romance is over: Follower perspectives of aversive leadership, Applied Psychology: An International Review 56 (4) (2007), pp. 528-557.

Bligh and Schyns, 20074 M. C. Bligh and B. Schyns, The romance lives on: Contemporary issues surrounding the romance of leadership, Leadership 3 (3) (2007), pp. 343-360.

Bresnen, 1995 M. J. Bresnen, All things to all people? Perceptions, attributions, and constructions of leadership, The Leadership Quarterly 6 (4) (1995), pp. 495-513.

Bryman, 19864 A. Bryman, Leadership in organizations, Routledge, London (1986).

Bryman, 19964 A. Bryman, Leadership in organizations. In: S. R. Clegg, C. Hardy, and W. Nord, eds., Handbook of organization studies, Sage Publications, London (1996), pp. 276-292.

Bryman, 20044 A. Bryman, Qualitative research on leadership: A critical by appreciative review, The Leadership Quarterly 15 (2004), pp. 729-769.

Campbell and Martinko, 1998 <. R. Campbell and M. J. Martinko, An integrative attributional perspective of empowerment and learned helplessness: A multimethod field study, Journal of Management 24 (2) (1998), pp. 173-200.

Carson et al., 20074 J. B. Carson, P. E. Tesluk, and J. A. Marrone, Shared leadership in teams: An investigation of antecedent conditions and performance, Academy of Management Journal 50 (5) (2007), pp. 1217-1234.

Chaleff, 19954 I. Chaleff, The courageous follower: Standing up to and for our leaders, Berrett-Koehler, San Francisco, CA (1995).

Cohen, $1958 \varangle$ A. R. Cohen, Upward communication in experimentally created hierarchies, Human Relations 11 (1958), pp. 41-53.

Cohen, $19604 \mathrm{~J}$. Cohen, A coefficient of agreement for nominal scales, Educational and Psychological Measurement 20 (1960), pp. 37-46.

Collinson, $2006 \varangle$ D. Collinson, Rethinking followership: A post-structuralist analysis of follower identities, The Leadership Quarterly 17 (2) (2006), pp. 179-189.

Conger, $1998<\mathrm{J}$. A. Conger, Qualitative research as the cornerstone methodology for understanding leadership, The Leadership Quarterly 9 (1) (1998), pp. 107-121.

Courpasson and Dany, 20034 D. Courpasson and F. Dany, Indifference or obedience? Business firms as democratic hybrids, Organization Studies 24 (8) (2003), pp. 1231-1260.

Deluga and Perry, $1991 \triangleleft$ R. J. Deluga and J. T. Perry, The relationship of subordinate upward influencing behaviour, satisfaction and perceived superior effectiveness with leader-member exchanges, Journal of Occupational Psychology 64 (3) (1991), pp. 239-252.

Dixon and Westbrook, 20034 G. Dixon and J. Westbrook, Followers revealed, Engineering Management Journal 15 (1) (2003), pp. 19-25.

Dvir and Shamir, $20034 \mathrm{~T}$. Dvir and B. Shamir, Follower developmental characteristics as predicting transformational leadership: A longitudinal field study, The Leadership Quarterly 14 (3) (2003), pp. 327-344.

Earley and Gibson, $1998<$ C. P. Earley and C. B. Gibson, Taking stock in our progress on individualism-collectivism: 100 years of solidarity and community, Journal of Management 24 (3) (1998), pp. 265-304.

Eden and Leviatan, $1975 \triangleleft$ D. Eden and U. Leviatan, Implicit leadership theory as a determinant of the factor structure underlying supervisory behavior scales, Journal of Applied Psychology 60 (1975), pp. 736-741.

Ehrhart and Klein, $2001<$ M. G. Ehrhart and K. J. Klein, Predicting followers' preferences for charismatic leadership: The influence of follower values and personality, The Leadership Quarterly 12 (2) (2001), pp. 153-179.

Ensley and Pearce, 20014 M. D. Ensley and C. L. Pearce, Shared cognition in top management teams: Implications for new venture performance, Journal of Organizational Behavior 22 (2) (2001), pp. 145-160.

Epitropaki and Martin, $2005<$ O. Epitropaki and R. Martin, From ideal to real: A longitudinal study of the role of implicit leadership theories on leader-member exchanges and employee outcomes, Journal of Applied Psychology 90 (2005), pp. 659-676.

Erez and Earley, 1987 M. Erez and C. P. Earley, Comparative analysis of goal-setting strategies across cultures, Journal of Applied Psychology 72 (4) (1987), pp. 658-665.

Fiske and Taylor, 1991 S. T. Fiske and S. E. Taylor, Social cognition (2nd ed.), McGraw-Hill, New York, NY (1991)

Follett, 19494 M. P. Follett, The essentials of leadership, Management Publications Trust, Ltd., London (1949).

Gerber, $1988 \varangle$ G. L. Gerber, Leadership roles and the gender stereotype traits, Sex Roles 18 (11-12) (1988), pp. 649-668.

Glauser, 19844 M. J. Glauser, Upward information flow in organizations: Review and conceptual analysis, Human Relations 37 (1984), pp. 613-643.

Graen and Uhl-Bien, $1995<$ G. B. Graen and M. Uhl-Bien, Relationship-based approach to leadership: Development of leader-member exchange (LMX) theory of leadership over 25 years: Applying a multi-level multi-domain perspective, The Leadership Quarterly 6 (2) (1995), pp. 219-247.

Greene, 19754 C. N. Greene, The reciprocal nature of influence between leader and subordinate, Journal of Applied Psychology 60 (1975), pp. 187-193.

Goetz and LeCompte, $19814 \mathrm{~J}$. Goetz and M. LeCompte, Ethnographic research and the problem of data reduction, Anthropology and Education Quarterly 12 (1981), pp. 51-70.

Harris, $1994<$ S. G. Harris, Organizational culture and individual sensemaking: A schema-based perspective, Organization Science 5 (3) (1994), pp. 309-321.

Hecksher, $1994 \varangle$ C. Hecksher, Defining the post-bureaucratic type. In: C. Heckscher and A. Donnellon, eds., The post-bureaucratic organization: New perspectives on organizational change, Sage, Newbury Park, CA (1994). 
Heenan and Bennis, 19994 D. A. Heenan and W. B. Bennis, Co-leaders: The power of great partnerships, John Wiley \& Sons, Inc., New York (1999).

Hickman, 2004 G. Hickman, Invisible leadership. In: G. R. Goethals, G. J. Sorenson, and J. M. Burns, eds., Encyclopedia of leadership, Berkshire/ Sage Reference (2004), pp. 750-754.

Hiller et al., 20064 N. J. Hiller, D. V. Day and R. J. Vance, Collective enactment of leadership roles and team effectiveness: A field study, The Leadership Quarterly 17 (4) (2006), pp. 387-397.

Hirschhorn, 19904 L. Hirschhorn, Leaders and followers in a postindustrial age: A psychodynamic view, Journal of Applied Behavioral Science 26 (4) (1990), pp. 529-542.

Hofstede, 19804 G. Hofstede, Culture's consequences: International differences in work-related values, Sage, Newbury Park, CA (1980).

Hollander, 19924 E. P. Hollander, Leadership, followership, self, and others, The Leadership Quarterly 3 (1992), pp. 43-54.

Hollander and Webb, 1955 E. P. Hollander and W. B. Webb, Leadership, followership, and friendship: An analysis of peer nominations, Journal of Abnormal and Social Psychology 50 (1955), pp. 163-167.

Holyoak and Gordon, 1984 K. J. Holyoak and P. C. Gordon, Information processing and social cognition. In: R. S. Wyer and T. K. Srull, eds., Handbook of social cognition, vol. 1, Lawrence Erlbaum, Hillsdale, NJ (1984), pp. 39-70.

Hooker et al., $2003 \varangle$ C. Hooker, J. Nakamura and M. Csikszentmihalyi, The group as mentor: Social capital and the systems model of creativity. In: P. B. Paulus and B. A. Nijstad, eds., Group creativity: Innovation through collaboration, Oxford University Press, New York, NY (2003), pp. 225-244.

Howell and Shamir, $20054 \mathrm{~J}$. M. Howell and B. Shamir, The role of followers in the charismatic leadership process: Relationships and their consequences, Academy of Management Review 30 (1) (2005), pp. 96-112.

Hunter et al., 2007 S. T. Hunter, K. E. Bedell-Avers, and M. D. Mumford, The typical leadership study: Assumptions, implications, and potential remedies, The Leadership Quarterly 18 (5) (2007), pp. 425-446.

Kark et al., $2003 \varangle$ R. Kark, B. Shamir, and G. Chen, The two faces of transformational leadership: Empowerment and dependency, Journal of Applied Psychology 88 (2) (2003), pp. 246-255.

Katz, 19834 J. Katz, A theory of qualitative methodology. In: R. M. Emerson, ed., Contemporary field research: A collection of readings, Prospect Heights, Ill, Waveland (1983), pp. 127-148.

Kelley, 1951 H. H. Kelley, Communication in experimentally created hierarchies, Human Relations 4 (1951), pp. 39-56.

Kelley, $1992 \varangle$ R. E. Kelley, The power of followership: How to create leaders people want to follow and followers who lead themselves, Doubleday, New York (1992).

Kipnis et al., $1981<$ D. Kipnis, S. Schmidt, K. Price and C. Sitt, Why do I like thee: Is it your performance or my orders?, Journal of Applied Psychology 66 (3) (1981), pp. 324-328.

Konst and Van Breukelen, 2005 D. Konst and W. Van Breukelen, Effects of hierarchical positions of target persons on social inference: Schema use and schema content in perceiving leaders and subordinates. In: B. Schyns and J. R. Meindl, eds., Implicit leadership theories: Essays and explorations, Information Age Publishing, Greenwich, CT (2005), pp. 305-332.

Lant and Shapira, $2000 \div$ T. K. Lant and Z. Shapira, Managerial and organizational cognition: Computation and interpretation, Lawrence Erlbaum Associates, Mahwah, NJ (2000).

Lee, 19994 T. W. Lee, Using qualitative methods in organizational research, Sage, Thousand Oaks, Ca (1999).

Lee et al., 19994 T. W. Lee, T. R. Mitchell and C. J. Sablynski, Qualitative research in organizational and vocational psychology, 1979-1999, Journal of Vocational Behavior 55 (1999), pp. 161-187.

Logan and Ganster, 2007 M. S. Logan and D. C. Ganster, The effects of empowerment on attitudes and performance: The role of social support and empowerment beliefs, Journal of Management Studies 44 (8) (2007), pp. 1523-1550.

Lord and Brown, 2004 R. G. Lord and D. J. Brown, Leadership processes and follower self-identity, Lawrence Erlbaum Associates Publishers, Mahwah, NJ (2004).

Lord and Hall, 20034 R. G. Lord and R. J. Hall, Identity, leadership categorization, and leadership schema. In: D. van Knippenberg and M. A. Hogg, eds., Leadership and power: Identity processes in groups and organizations, SAGE, London (2003), pp. 48-64.

Lord and Maher, 1991 R. G. Lord and K. L. Maher, Leadership and information processing: Linking perceptions with performance, Unwin Hyman, Boston (1991).

Louis, $19804 \mathrm{M}$. R. Louis, Surprise and sense making: What newcomers experience in entering unfamiliar organizational settings, Administrative Science Quarterly 25 (1980), pp. 226-251.

Lovelace et al., 2007 K. J. Lovelace, C. Manz, and J. C. Alves, Work stress and leadership development: The role of self-leadership, shared leadership, physical fitness and flow in managing demands and increasing job control, Human Resource Management Review 17 (4) (2007), pp. 374-387.

Lowin and Craig, 1968 A. Lowin and J. R. Craig, The influence of level of performance on managerial style: An experimental object lesson in the ambiguity of correlational data, Organizational Behavior and Human Performance 3 (1968), pp. 441-458.

Manz, 1986 C. C. Manz, Self-leadership: Toward an expanded view of self-influence processes in organizations, Academy of Management Review 11 (3) (1986), pp. 585-600.

Manz and Sims, 1980 C. C. Manz and H. P. Sims Jr., Self-management as a substitute for leadership: A social learning perspective, Academy of Management Review 5 (1980), pp. 361-367.

Mayhew et al., 2007 M. G. Mayhew, N. M. Ashkanasy and T. Bramble, A study of the antecedents and consequences of psychological ownership in organizational settings, Journal of Social Psychology 147 (5) (2007), pp. 477-500.

Meindl, 19954 J. R. Meindl, The romance of leadership as a follower-centric theory: A social constructionist approach, The Leadership Quarterly 6 (1995), pp. 329-341.

Meindl and Ehrlich, 1987 J. R. Meindl and S. B. Ehrlich, The romance of leadership and the evaluation of organizational performance, Academy of Management Journal 30 (1) (1987), pp. 91-109.

Meindl et al., 1985 J. R. Meindl, S. B. Ehrlich and J. M. Dukerich, The romance of leadership, Administrative Science Quarterly 30 (1985), pp. 78-102.

Miles and Huberman, 1994 M. B. Miles and A. M. Huberman, Qualitative data analysis: An expanded sourcebook (2nd ed.), Sage, Thousand Oaks (1994).

Milgram, 1965 S. Milgram, Some conditions of obedience and disobedience to authority, Human Relations 18 (1965), pp. 57-76.

Milliken et al., $2003<$ F. J. Milliken, E. W. Morrison, and P. F. Hewlin, An exploratory study of employee silence: Issues that employees don't communicate upward and why, Journal of Management Studies 40 (6) (2003), pp. 1453-1476.

Morand, $1996 \varangle$ D. Morand, Dominance, deference and egalitarianism in organizational interaction: A sociolinguistic analysis of power and politeness, Organization Science 7 (5) (1996), pp. 544-556.

Morrison and Milliken, $2000<$ E. W. Morrison and F. J. Milliken, Organizational silence: A barrier to change and development in a pluralistic world, Academy of Management Review 25 (4) (2000), pp. 706-725.

Morrison and Phelps, 1999 E. W. Morrison and C. C. Phelps, Taking charge at work: Extra role efforts to initiate workplace change, Academy of Management Journal 42 (4) (1999), pp. 403-419.

Near and Jensen, $1983<\mathrm{J}$. P. Near and T. C. Jensen, The whistle blowing process: Retaliation and perceived effectiveness, Work and Occupations 10 (1) (1983), pp. 3-28. 
Neck et al., 1999 C. P. Neck, H. M. Neck, C. C. Manz and J. Godwin, 'I think I can; I think I can': A self-leadership perspective toward enhancing entrepreneur thought patterns, self-efficacy, and performance, Journal of Managerial Psychology 14 (5-6) (1999), pp. 477-501.

Pastor et al., 2007 J. C. Pastor, M. Mayo and B. Shamir, Adding fuel to fire: The impact of followers' arousal on ratings of charisma, Journal of Applied Psychology 92 (6) (2007), pp. 1584-1596.

Patton, 20024 M. Q. Patton, Qualitative research and evaluation methods (3rd edition), Thousand Oaks, Sage (2002).

Pearce, $1997<$ C. L. Pearce, The determinants of change management team effectiveness: A longitudinal investigation. Ph.D. dissertation. University of Maryland, College Park (1997).

Pearce and Conger, 2003 C. L. Pearce and J. A. Conger, Shared leadership: Reframing the hows and whys of leadership, Sage Publications, Thousand Oaks, CA (2003).

Pearce and Manz, 20054 C. L. Pearce and C. C. Manz, The new silver bullets of leadership: The importance of self- and shared leadership in knowledge work, Organizational Dynamics 34 (2) (2005), pp. 130-140.

Pearce and Sims, $2002<$ C. L. Pearce and H. P. Sims, Vertical versus shared leadership as predictors of the effectiveness of change management teams: An examination of aversive, directive, transactional, transformational, and empowering leader behaviors, Group Dynamics: Theory, Research, and Practice 6 (2) (2002), pp. 172-197.

Pearce et al., $2004 \varangle$ C. L. Pearce, Y. Yoo and M. Alavi, Leadership, social work, and virtual teams: The relative influence of vertical versus shared leadership in the nonprofit sector. In: R. Riggio and S. Orr, eds., Improving leadership in nonprofit organizations, Jossey-Bass, San Francisco, CA, US (2004), pp. 180-203.

Phillips and Bedeian, 1994 A. S. Phillips and A. G. Bedeian, Leader-follower exchange quality: The role of personal and interpersonal attributes, Academy of Management Journal 37 (4) (1994), pp. 990-1001.

Pillai et al., 2007 R. Pillai, J. C. Kohles and M. C. Bligh, Through thick and thin? Follower constructions of presidential leadership amidst crisis, 2001-2005. In: B. Shamir, R. Pillai, M. C. Bligh and M. Uhl-Bien, eds., Follower-centered perspectives on leadership: A tribute to the memory of James R. Meindl, Information Age Publishing, Greenwich, CT (2007), pp. 135-166.

Porter and McLaughlin, 2006 L. W. Porter and G. B. McLaughlin, Leadership and the organizational context: Like the weather?, The Leadership Quarterly 17 (6) (2006), pp. 559-576.

Ravlin and Thomas, 2005 E. C. Ravlin and D. C. Thomas, Status and stratification in organizational life, Journal of Management 31 (6) (2005), pp. 966-987.

Ridgeway and Walker, 1995 C. L. Ridgeway and H. A. Walker, Status structures. In: K. S. Cook, G. A. Fine and J. S. House, eds., Sociological perspectives on social psychology, Allyn \& Bacon, Boston, MA (1995), pp. 281-310.

Roberts and O'Reilly, $1974 \varangle \mathrm{K}$. H. Roberts and C. A. O'Reilly, Failure in upward communication: Three possible culprits, Academy of Management Journal 17 (2) (1974), pp. 205-215.

Rodrigues, 1990 C. A. Rodrigues, The situation and national culture as contingencies for leadership behaviour: Two conceptual models. In: S. B. Prasad, ed., Advances in international comparative management: A research annual Vol. 5, JAJ Press, Greenwich, CT (1990), pp. 51-68.

Rost, 1995 J. C. Rost, Leadership: A discussion about ethics, Business Ethics Quarterly 5 (1) (1995), pp. 129-142.

Schyns and Felfe, $2006<$ B. Schyns and J. Felfe, The personality of followers and its effect on the perception of leadership: An overview, a study, and a research agenda, Small Group Research 37 (5) (2006), pp. 522-539.

Seibert et al., 20044 S. E. Seibert, S. R. Silver, and A. W. Randolph, Taking empowerment to the next level: A multiple-level model of empowerment, performance, and satisfaction, Academy of Management Journal 47 (3) (2004), pp. 332-349.

Shamir, 2007 B. Shamir, From passive recipients to active co-producers: Followers' roles in the leadership process. In: B. Shamir, R. Pillai, M. C. Bligh, and M. Uhl-Bien, eds., Follower-centered perspectives on leadership: A tribute to the memory of James R. Meindl, Information Age Publishing, Greenwich, CT (2007), pp. ix-xxxix.

Shamir and Lapidot, $2003<$ B. Shamir and Y. Lapidot, Trust in organizational superiors: Systemic and collective considerations, Organization Studies 24 (3) (2003), pp. 463-491.

Shamir et al., 2007 B. Shamir, R. Pillai, M. C. Bligh, and M. Uhl-Bien, Follower-centered perspectives on leadership: A tribute to the memory of James R. Meindl, Information Age Publishing, Greenwich, CT (2007).

Smircich and Morgan, 1982 L. Smircich and G. Morgan, Leadership: The management of meaning, Journal of Applied Behavioral Science 18 (1982), pp. 257-273.

Spreitzer and Doneson, 20054 G. M. Spreitzer and D. Doneson, Musings on the past and future of employee empowerment. In: T. Cummings, ed., Handbook of organizational development, Sage, Thousand Oaks (2005).

Srivastava et al., 2006 A. Srivastava, K. M. Bartol and E. A. Locke, Empowering leadership in management teams: Effects on knowledge sharing, efficacy, and performance, Academy of Management Journal 49 (6) (2006), pp. 1239-1251.

Strauss and Corbin, 1998 A. L. Strauss and L. Corbin, Basics of qualitative research: A grounded theory procedures and techniques, Sage Publications, Newbury Park CA (1998).

Thomas and Velthouse, $1990 \varangle \mathrm{K}$. W. Thomas and B. A. Velthouse, Cognitive elements of empowerment: An 'interpretive' model of intrinsic task motivation, Academy of Management Review 15 (4) (1990), pp. 666-681.

Tyler, $1997 \varangle$ T. R. Tyler, The psychology of legitimacy: A relational perspective on voluntary deference to authorities, Personality and Social Psychology Review 1 (4) (1997), pp. 323-345.

Tynan, 2005 R. Tynan, The effects of threat sensitivity and face-giving on dyadic psychological safety and upward communication, Journal of Applied Social Psychology 35 (2) (2005), pp. 223-247.

Uhl-Bien and Carsten, 2007 M. Uhl-Bien and M. K. Carsten, Being ethical when the boss is not, Organizational Dynamics 36 (2) (2007), pp. 187-201.

Uhl-Bien et al., $20004 \mathrm{M}$. Uhl-Bien, G. B. Graen, and T. Scandura, Implications of leader-member exchange (LMX) for strategic human resource management systems: Relationships as social capital for competitive advantage. In: G. Ferris, ed., Research in personnel and human resource management Vol. 18, JAI Press, Greenwich, CT (2000), pp. 137-185.

Uhl-Bien and Pillai, 2007 M. Uhl-Bien and R. Pillai, The romance of leadership and the social construction of followership. In: B. Shamir, R. Pillai, M. C. Bligh and M. Uhl-Bien, eds., Follower-centered perspectives on leadership: A tribute to the memory of James R. Meindl, Information Age Publishing, Greenwich, CT (2007), pp. 187-209.

Van Dyne and LePine, 1998 L. Van Dyne and J. A. LePine, Helping and voice extra-role behaviors: Evidence of construct and predictive validity, Academy of Management Journal 41 (3) (1998), pp. 108-119.

Vroom and Mann, $1960<$ V. H. Vroom and F. C. Mann, Leader authoritarianism and employee attitudes, Personnel Psychology 13 (1960), pp. $125-140$.

Weick, 1993 K. E. Weick, The collapse of sensemaking in organizations: The Mann Gulch disaster, Administrative Science Quarterly 38 (1993), pp. 628-652.

Weick, 1995 K. E. Weick, Sensemaking in organizations, Sage, Thousand Oaks, Ca (1995).

Wortman, 1982 M. S. Wortman Jr., Strategic management and changing leader-follower roles, Journal of Applied Behavioral Sciences 18 (1982), pp. 371-383.

Yun et al., 2006 S. Yun, J. Cos and H. P. Sims, The forgotten follower, Journal of Managerial Psychology 21 (4) (2006), pp. 374-386. 